\title{
DETERMINAÇÃO EXPERIMENTAL DA SOLUBILIDADE DO FERTILIZANTE URÉIA EM SOLVENTES PUROS
}

\author{
F. M. A. S. $\operatorname{COSTA}^{1}$, A. P. SILVA ${ }^{1}$, M. R. FRANCO JÚNIOR ${ }^{1}$ e R. A. MALAGONI ${ }^{1}$ \\ ${ }^{1}$ Universidade Federal de Uberlândia, Faculdade de Engenharia Química \\ E-mail para contato: malagoni@feq.ufu.br
}

\begin{abstract}
RESUMO - Existem várias referências onde a solubilidade da ureia e seu comportamento em solução influenciam o sistema. Assim, o levantamento de dados de solubilidade contribui para a promoção de diversos estudos científicos. Neste trabalho foi determinada experimentalmente a solubilidade da ureia em água, etanol, isopropanol e metanol, em temperaturas de 278,2 a 333,2 K à pressão atmosférica constante. Para obtenção dos dados experimentais, utilizou-se o método gravimétrico. O experimento foi realizado em temperatura constante com 2 horas de agitação seguido de 2 horas de decantação. Realizou-se uma coleta de dados e posteriormente fizeram-se os cálculos da solubilidade da ureia, os quais são baseados no método gravimétrico. Garantiu-se que o método gravimétrico é satisfatório para a determinação de solubilidade da ureia, já que os desvios experimentais foram baixos.
\end{abstract}

\section{INTRODUÇÃO}

A solubilidade é definida como sendo a concentração de soluto em uma solução saturada. Esta é formada quando uma dada quantidade de solvente permite a solubilização de uma quantidade máxima de soluto a uma dada temperatura (Derenzo, 2003). As forças intermoleculares entre o soluto e o solvente são fatores que influenciam na solubilidade (Maia, 2007). A solubilidade, ou condição de saturação, é experimentalmente determinada pelo aquecimento da suspensão e observando-se em qual temperatura todo o sólido se dissolve (NÝVLT et al., 2001).

O fertilizante ureia é um produto sólido que se apresenta na forma de grânulos brancos, contém $46 \%$ de nitrogênio, sendo higroscópico e solúvel em água, álcool e benzina e com uso na agricultura. A ureia é um sólido não inflamável, mas corrosivo (PETROBRAS, 2014).

A utilização da ureia possibilita a complementação da quantidade necessária de nitrogênio no solo, para que se obtenha melhor produtividade nas culturas. A ureia também reduz os custos de adubação, transporte, armazenagem e aplicação, é menos acidificante que outros fertilizantes nitrogenados e possui grande eficiência em aplicações foliares (PETROBRAS, 2014).

O estudo da solubilidade da ureia é relevante para a aplicação desta no solo, para o projeto de equipamentos industriais, estudos de cristalização e nucleação, além de ser usado para aperfeiçoar os processos de separação já existentes. 
O comportamento da ureia em solução é um tópico de extrema importância em estudos biológicos e ambientais, devido ao seu envolvimento como um produto residual em nossa vida diária. As interações de solutos pouco solúveis em soluções aquosas de ureia são de interesse contemporâneo, tanto a nível teórico como prático (KUMARAN et al., 2006).

\section{MATERIAIS E MÉTODOS}

\subsection{Unidade Experimental}

O aparato utilizado para realização dos experimentos foi constituído por dois vasos encamisados de vidro pyrex, com $50 \mathrm{~mL}$ de volume interno, conectados em série, nomeados de células de equilíbrio. Mangueiras de látex interligavam as células e as conectavam a um banho termostatizado. O banho tinha como função manter constante a temperatura dentro da célula. A camisa externa das células, por onde circulava água advinda do banho, foi responsável por fornecer a termostatização da mistura. As células eram apoiadas em dois agitadores magnéticos e com o auxílio de uma barra magnética promovia a agitação da solução. As células eram vedadas com rolhas de tecnyl, as quais serviram como suporte para os termopares. Foram utilizados dois indicadores digitais acoplados aos termopares para aferir a temperatura dentro da célula. Esses termopares foram fixados nas rolhas de tecnyl e introduzidos pela parte superior da célula de forma que os termopares ficassem no seio da mistura. A Figura 1 mostra a unidade experimental.

Figura 1 - Unidade Experimental.

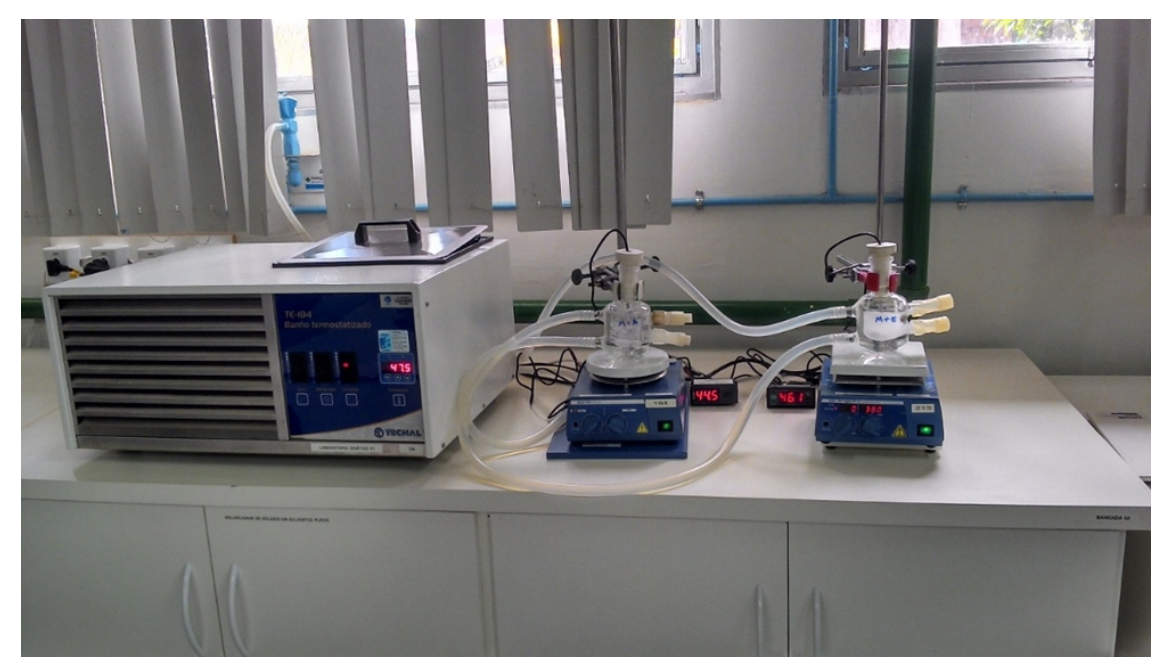

\subsection{Procedimento Experimental}

As células foram colocadas sobre os agitadores magnéticos e conectadas em série com o banho termostático através de mangueiras de látex. O banho termostatizado foi ligado na temperatura desejada a fim de se estabilizá-la. As células foram vedadas com rolhas de tecnyl com termopares acoplados de forma que ficassem no seio da célula. 
Foi introduzido nas células o solvente previamente preparado. Em seguida, as barras magnéticas foram adicionadas e a agitação foi ligada. Quando os termopares marcaram uma temperatura próxima a desejada, a ureia foi introduzida em excesso até que se obtivesse corpo de fundo na célula.

Com a temperatura estabilizada, começava a contagem do tempo de agitação. A agitação ocorria durante duas horas, seguida por duas horas de decantação. Terminado o tempo de decantação, realizava-se a amostragem com o auxílio de uma seringa de vidro de 10 $\mathrm{mL}$. Esta seringa foi mantida em um béquer que estava dentro do banho termostatizado, a fim de que não houvesse precipitação de ureia dentro da seringa. Foram retiradas de cada célula 4 amostras com cerca de $5 \mathrm{~mL}$ cada. As amostras foram retiradas da parte de cima da célula para que não fossem amostrados traços de ureia que estavam no fundo das células.

Os béqueres, previamente limpos e secos, foram identificados e pesados vazios para que fossem utilizados nas amostragens. Após a retirada do líquido sobrenadante de cada célula, os béqueres com as amostras foram quantificados em uma balança analítica com precisão de 0,0001g e colocados por 24 horas em uma estufa a 338,2 K. Decorrido este tempo, eram retirados da estufa e mantidos por 30 minutos dentro de um dessecador com sílica gel. Em seguida foram quantificados. Tal procedimento foi repetido até que a massa da ureia se mantivesse constante, cerca de 4 dias.

Para cada temperatura foi feita a média aritmética dos valores de solubilidade encontrados nas amostras, para isto utilizou-se a Equação 1. Todo este procedimento foi realizado para cada faixa de temperatura. Com isto, determinou-se a solubilidade do composto em diferentes temperaturas.

$$
S=\frac{m_{\text {ureia seca }}}{m_{\text {solvente }}} \times 100
$$


solvente também expressa em gramas.

O procedimento experimental adotado neste trabalho foi baseado nos procedimentos já reportados nos trabalhos de Silva et al. (2014), Maionchi et al. (2014) e Lee e Lahti (1972).

\section{RESULTADOS E DISCUSSÃO}

Os dados de solubilidade obtidos com o auxílio do método gravimétrico para os sistemas ureia + água, ureia + etanol, ureia + isopropanol e ureia + metanol, juntamente com os desvios padrões para cada temperatura são apresentados pela Tabela 1. Os valores de solubilidade e dos desvios estão expressos em fração molar da ureia na solução. A temperatura está expressa em Kelvin. As curvas de solubilidade da ureia nos quatro solventes em função da temperatura estão representadas na Figura 2. 
Tabela 1 - Dados experimentais da solubilidade da ureia em água, etanol, isopropanol e metanol.

\begin{tabular}{|c|c|c|c|c|}
\hline \multirow{2}{*}{$T(\mathrm{~K}) \pm \sigma$} & Ureia + Água & Ureia + Etanol & Ureia + Isopropanol & Ureia + Metanol \\
\hline & $y_{\exp } \pm \delta$ & $y_{\exp } \pm \delta$ & $y_{\exp } \pm \delta$ & $y_{\exp } \pm \delta$ \\
\hline $\begin{array}{c}278,2 \pm \\
0,3\end{array}$ & $0,1819 \pm 0,0005$ & $0,0278 \pm 0,0005$ & $0,0217 \pm 0,0001$ & $0,0771 \pm 0,0005$ \\
\hline $\begin{array}{c}283,4 \pm \\
0,3\end{array}$ & $0,2013 \pm 0,0002$ & $0,0335 \pm 0,0001$ & $0,0259 \pm 0,0004$ & $0,0900 \pm 0,0004$ \\
\hline $\begin{array}{c}288,2 \pm \\
0,1\end{array}$ & $0,2212 \pm 0,0006$ & $0,0344 \pm 0,0002$ & $0,0288 \pm 0,0002$ & $0,0940 \pm 0,0001$ \\
\hline $\begin{array}{c}293,2 \pm \\
0,1\end{array}$ & $0,2411 \pm 0,0003$ & $0,0387 \pm 0,0003$ & $0,0308 \pm 0,0006$ & $0,1071 \pm 0,0005$ \\
\hline $\begin{array}{c}298,3 \pm \\
0,2\end{array}$ & $0,2664 \pm 0,0004$ & $0,0439 \pm 0,0008$ & $0,0373 \pm 0,0002$ & $0,1184 \pm 0,0001$ \\
\hline $\begin{array}{c}303,3 \pm \\
0,1\end{array}$ & $0,2891 \pm 0,0007$ & $0,0505 \pm 0,0002$ & $0,0393 \pm 0,0001$ & $0,1330 \pm 0,0004$ \\
\hline $\begin{array}{c}308,2 \pm \\
0,1\end{array}$ & $0,3117 \pm 0,0008$ & $0,0564 \pm 0,0002$ & $0,0451 \pm 0,0001$ & $0,1468 \pm 0,0003$ \\
\hline $\begin{array}{c}313,1 \pm \\
0,1\end{array}$ & $0,3342 \pm 0,0071$ & $0,0611 \pm 0,0003$ & $0,0530 \pm 0,0003$ & $0,1587 \pm 0,0019$ \\
\hline $\begin{array}{c}318,1 \pm \\
0,1\end{array}$ & $0,3591 \pm 0,0014$ & $0,0683 \pm 0,0002$ & $0,0593 \pm 0,0001$ & $0,1839 \pm 0,0014$ \\
\hline $\begin{array}{c}323,3 \pm \\
0,0\end{array}$ & $0,3724 \pm 0,0038$ & $0,0799 \pm 0,0013$ & $0,0658 \pm 0,0008$ & $0,2076 \pm 0,0011$ \\
\hline $\begin{array}{c}328,2 \pm \\
0,1\end{array}$ & $0,4018 \pm 0,0033$ & $0,0860 \pm 0,0014$ & $0,0671 \pm 0,0010$ & $0,2304 \pm 0,0015$ \\
\hline $\begin{array}{c}333,3 \pm \\
0,1 \\
\end{array}$ & $0,4262 \pm 0,0173$ & $0,0946 \pm 0,0024$ & $0,0735 \pm 0,0019$ & $0,2650 \pm 0,0021$ \\
\hline
\end{tabular}

Analisando a Tabelas 1 e a Figuras 2, observa-se que em todos os sistemas a solubilidade da ureia aumenta em função do aumento da temperatura, como já era esperado, pois o sistema é endotérmico, nesta faixa de temperatura. Percebe-se também que, a solubilidade da ureia é maior em água, seguida do metanol, etanol e é menor em isopropanol. Analisando as propriedades de cada solvente, tem-se que o isopropanol é o menos polar dos solventes utilizados e a água é o mais polar. Então é possível concluir que a solubilidade da ureia é maior em solventes polares, ou seja, a ureia se dissolve melhor em solventes fortemente polares 
Figura 2 - Solubilidade da ureia em água, metanol, etanol e isopropanol

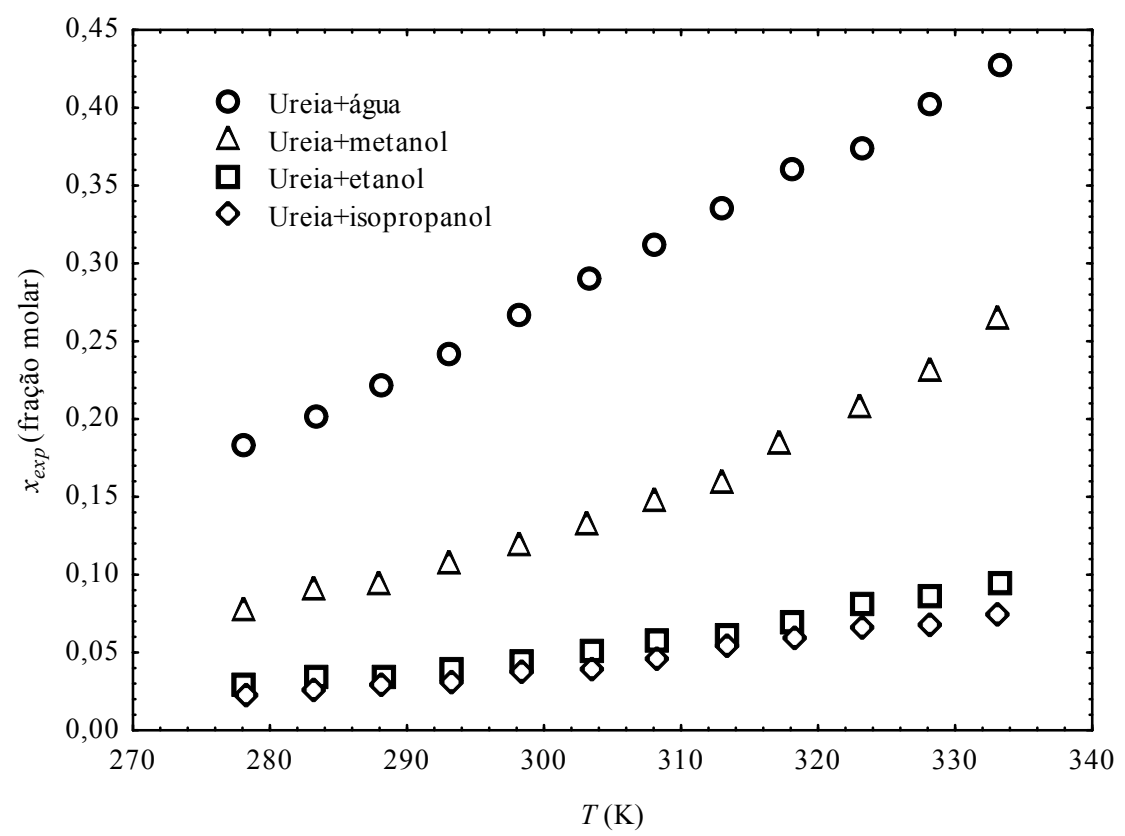

\section{CONCLUSÃO}

Com base nos resultados obtidos, pode-se concluir que todas as curvas de solubilidade foram replicadas com baixos valores de desvios percentuais, o que sugere uma boa reprodutibilidade dos dados experimentais e que o aparato experimental foi eficiente para determinar a solubilidade de ureia em diversos solventes.

A água apresentou os maiores valores de solubilidade para a ureia. Isso se deve ao fato da solubilidade da ureia ser diretamente proporcional à constante dielétrica dos solventes. A água é o solvente com maior constante dielétrica e também o mais polar dentre os solventes utilizados.

\section{REFERÊNCIAS}

DERENZO, S. Cristalização de ácido adípico em diferentes solventes. Tese de Doutorado. Departamento de Engenharia Química, Universidade Federal de São Carlos, São Carlos-SP. 180 p.

KUMARAN, P.; RAMAMURTHY, P. PET suppression of acridinedione dyes by urea derivatives in water and methanol. Journal of Physical Chemistry B, v.110, n. 47, p.23783-23789, 2006.

LEE, F. M.; LAHTI, L. E. Solubility of urea in water-alcohol mixtures. Journal of Chemical and Engineering Data, v. 7, n. 3, p. 304-306, 1972. 
MAIA, G. D. Contribuição ao estudo termodinâmico das soluções de ácido acetilsalicílico. 2007. 159 p. Tese de Doutorado. Centro de Ciências Exatas e Tecnologia, Universidade Federal de São Carlos, São Carlos, 2007.

MAIONCHI, I. A., MOTTA, A. G. A. F., SilvA, A. P.; MALAGONI, R. A. Ajuste dos dados experimentais de solubilidade da ureia em misturas de isopropanol + água. In: CONGRESSO BRASILEIRO DE ENGENHARIA QUÍMICA, 20², 2014, Florianópolis. Anais do XX COBEQ, Florianópolis: UFSC, 2014.

NÝVLT, J.; HOSTOMSKÝ, J.; GIULIETTI, M. Cristalização. Brasil. Editor da UFSCar, p.160, 2001.

SILVA, A. P.; ANDRADE, R. A. F.; MALAGONI, R. A. Ensaios de solubilidade da ureia em etanol + água e metanol + água. In: CONGRESSO BRASILEIRO DE ENGENHARIA QUÍMICA, 20², 2014, Florianópolis. Anais do XX COBEQ, Florianópolis: UFSC, 2014. 